\title{
Prenatal Effects of Nicotine During Different Trimesters on Postnatal Development
}

DOI: http://dx.doi.org/10.5915/17-2_3-12751

Ghazi M. Al-Hachim, Ph.D.*

Faiza A. Mahmood, M.Sc.

\section{Abstract:}

Three different doses of nicotine were used daily for seven consecutive days, and administered during each trimester into three groups of 10 pregnant mice. The doses used were equivalent to 10 cigarettes $(900 \mathrm{~g} / \mathrm{kg})$, 20 cigarettes $(1800 \mu \mathrm{g} / \mathrm{kg})$ or 30 cigarettes $(400 \mu \mathrm{g} / \mathrm{kg})$. For each trimester and for each dose one sub-group of 10 offspring from drug or normal saline (control)-treated mothers were randomly selected and their postnatal developments were observed during the first and the second month of their age.

All the doses of the prenatal nicotine significantly reduced the body weight of the offspring at birth and postnatally.

Large doses of prenatal nicotine reduced the weight of the brain significantly during the second trimester. They also reduced the weights of the liver, heart and brain significantly during the third trimester. However, prenatal nicotine showed no effect on the weight of the kidney and the adrenal gland.

These results indicate that large doses of prenatal nicotine may retard the functions and/or the development of the vital systems of the nicotine-treated progenies if they were exposed to nicotine during the second and third trimesters.

Key Words: Prenatal nicotine, postnatal development, body, viscera, offspring, mice.

\section{Introduction}

Nicotine is metabolized in the liver, excreted within 24 hours via the kidney and crosses placental and brain barriers easily. Nicotine can substitute smoking, chewing and snuffing of tobacco. 7 It has been reported that prenatal nicotine reduces the postnatal growth of the offspring. 10 However, it has not been reported in which trimester of pregnancy during administration of nicotine is most effective on the postnatal development of the offspring. The present research aim is to find an answer to this question.

\section{Procedure}

Three different doses: small, intermediate or large of nicotine base were used and administered during each trimester into three groups of pregnant Swiss albino mice strain. The doses used were equivalent to 10 cigarettes $(900 \mu \mathrm{g} / \mathrm{kg}), 20$ cigarettes $(1800 \mu \mathrm{g} / \mathrm{kg})$ or 30 cigarettes $(2700 \mu \mathrm{g} / \mathrm{kg})$.

Each dose was subcutaneously administered daily during each trimester. The control group of the pregnant mice for each trimester were given normal saline solution subcutaneously too.

The body weight of the offspring for each trimester were measured on the birth day and weekly thereafter till they were 70 days old. For each trimester and for each dose one and two months old prenatally nicotinetreated subgroup and one control subgroup of 10 offsprings were randomly selected and killed by decapitation. Their viscera: adrenal glands, brain, liver,

From the Department of Pharmacology, College of Medicine, Baghdad, Iraq

Address all correspondence to Dr. Ghazi Al-Hachim, Professor of Pharmacology,

King Abdulaziz University, College of Medicine, P. O. Box 9029, Jeddah 21413, Saudi Arabia heart and kidneys were weighed, reported and subjected to statistical analysis by using stident T-test. ${ }^{8}$

\section{Results \\ FIRST TRIMESTER \\ Body Weight}

The results of the body weights of the offspring from mothers treated with nicotine during the first trimester are shown in Table 1 and Fig. 1.

Compared with the controls, there was highly significant $(p<.01)$ reduction in the birth weight of all prenatally nicotine-treated offspring for 4,6 and 9 postnatal weeks with the small, intermediate and large doses respectively. These findings indicate that the reduction in body weight was more obvious with the large dose than the small one (Fig. 1). In addition, they indicate that the severe reduction effect caused by the large dose disappeared when the offspring were 9 weeks old.

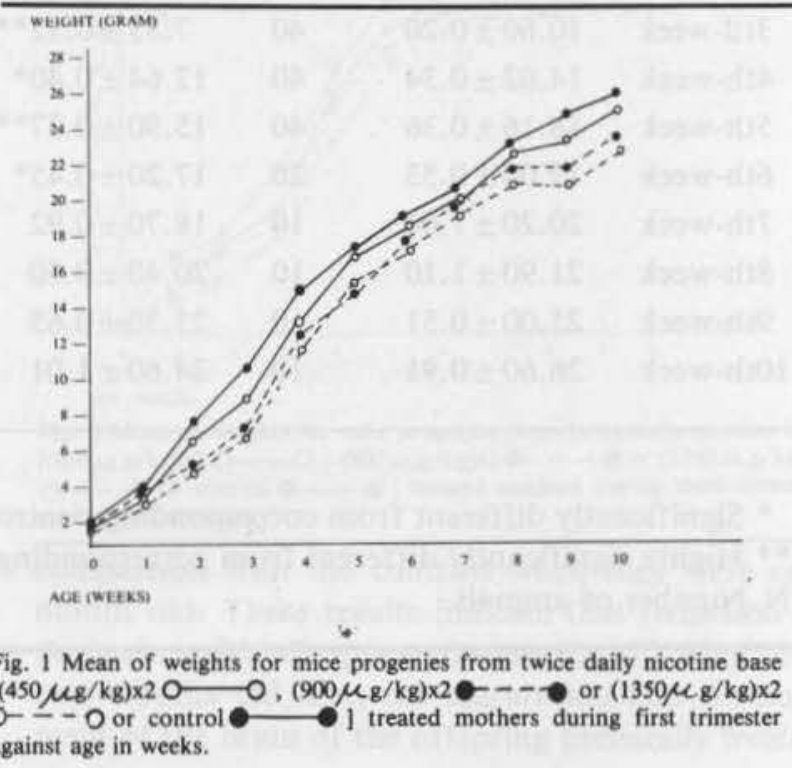


Table 1: The mean \pm S.E. of weights for mice progenies from twice daily nicotine base-or normal saline (control)-treated mothers during first trimester.

Mean \pm S.E.

\begin{tabular}{lcccccccc}
\hline Age & Control & $\mathrm{N}$ & $(450 \mu \mathrm{g} / \mathrm{kg}) \times 2$ & $\mathrm{~N}$ & $(900 \mu \mathrm{g} / \mathrm{kg}) \times 2$ & $\mathrm{~N}$ & $(1350 \mu \mathrm{g} / \mathrm{kg}) \times 2$ & $\mathrm{~N}$ \\
\hline Birth-day & $1.66 \pm 0.01$ & 80 & $1.53 \pm 0.02^{* *}$ & 60 & $1.47 \pm 0.02^{* *}$ & 60 & $1.41 \pm 0.02^{* *}$ & 60 \\
1st-week & $4.10 \pm 0.23$ & 40 & $3.37 \pm 0.16^{* *}$ & 30 & $3.28 \pm 0.12^{* *}$ & 30 & $3.33 \pm 0.11^{* *}$ & 30 \\
2nd-week & $7.23 \pm 0.18$ & 40 & $6.30 \pm 0.21^{* *}$ & 30 & $5.45 \pm 0.03^{* *}$ & 30 & $5.02 \pm 0.15^{* *}$ & 30 \\
3rd-week & $10.70 \pm 0.29$ & 40 & $8.74 \pm 0.23^{* *}$ & 30 & $7.31 \pm 0.21^{* *}$ & 30 & $7.06 \pm 0.24^{* *}$ & 30 \\
4th-week & $14.42 \pm 0.30$ & 40 & $13.13 \pm 0.26^{* *}$ & 30 & $12.33 \pm 0.26^{* *}$ & 30 & $11.80 \pm 0.37^{* *}$ & 30 \\
5th-week & $17.52 \pm 0.27$ & 40 & $16.63 \pm 0.46$ & 30 & $15.06 \pm 0.30^{* *}$ & 30 & $15.62 \pm 0.33^{* *}$ & 30 \\
6th-week & $19.00 \pm 0.35$ & 20 & $18.00 \pm 0.47$ & 20 & $17.80 \pm 0.28^{* *}$ & 20 & $17.20 \pm 0.52^{* *}$ & 20 \\
7th-week & $20.30 \pm 0.58$ & 10 & $19.90 \pm 0.11$ & 10 & $19.20 \pm 0.49$ & 10 & $19.10 \pm 0.16^{*}$ & 10 \\
8th-week & $22.70 \pm 0.63$ & 10 & $21.90 \pm 0.72$ & 10 & $21.40 \pm 0.48$ & 10 & $20.50 \pm 0.98^{*}$ & 10 \\
9th-week & $24.75 \pm 0.43$ & 10 & $22.90 \pm 0.70$ & 40 & $21.30 \pm 0.47$ & 10 & $20.37 \pm 0.39^{* *}$ & 10 \\
10th-week & $25.70 \pm 1.90$ & 10 & $24.50 \pm 0.92$ & 10 & $23.40 \pm 0.37$ & 10 & $23.20 \pm 0.65$ & 10 \\
& \\
\hline
\end{tabular}

Table 2: The mean \pm S.E. of weights for mice progenies from twice daily nicotine base-or normal saline (control)-treated mothers during second trimester.

Mean \pm S.E.

\begin{tabular}{rrrllllll}
\hline Age & Control & $\mathrm{N}$ & $(450 \mu \mathrm{g} / \mathrm{kg}) \times 2$ & $\mathrm{~N}$ & $(900 \mu \mathrm{g} / \mathrm{kg}) \times 2$ & $\mathrm{~N}$ & $(1350 \mu \mathrm{g} / \mathrm{kg}) \times 2$ & $\mathrm{~N}$ \\
\hline Birth-day & $1.62 \pm 0.01$ & 90 & $1.40 \pm 0.02^{* *}$ & 90 & $1.40 \pm 0.01^{* *}$ & 80 & $1.32 \pm 0.01^{* *}$ & 80 \\
1st-week & $4.02 \pm 0.24$ & 40 & $3.14 \pm 0.20^{*}$ & 40 & $3.63 \pm 0.10^{* *}$ & 40 & $3.10 \pm 0.11^{* *}$ & 40 \\
2nd-week & $7.24 \pm 0.16$ & 40 & $5.44 \pm 0.15^{* *}$ & 40 & $4.90 \pm 0.12^{* *}$ & 40 & $4.90 \pm 0.20^{* *}$ & 40 \\
3rd-week & $10.60 \pm 0.20$ & 40 & $7.35 \pm 0.32^{* *}$ & 40 & $6.66 \pm 0.23^{* *}$ & 40 & $6.50 \pm 0.21^{* *}$ & 40 \\
4th-week & $14.02 \pm 0.34$ & 40 & $12.64 \pm 0.40^{*}$ & 40 & $11.96 \pm 0.34^{* *}$ & 40 & $9.65 \pm 0.34^{* *}$ & 40 \\
5th-week & $18.16 \pm 0.36$ & 40 & $15.90 \pm 0.37^{* *}$ & 40 & $15.64 \pm 0.40^{* *}$ & 40 & $15.10 \pm 0.39^{* *}$ & 40 \\
6th-week & $19.00 \pm 0.53$ & 20 & $17.20 \pm 0.45^{*}$ & 20 & $16.40 \pm 0.54^{*}$ & 20 & $16.85 \pm 0.67^{*}$ & 20 \\
7th-week & $20.20 \pm 1.04$ & 10 & $18.70 \pm 0.92$ & 10 & $18.40 \pm 0.93$ & 10 & $18.30 \pm 1.02$ & 10 \\
8th-week & $21.90 \pm 1.10$ & 10 & $20.40 \pm 0.50$ & 10 & $19.40 \pm 1.00$ & 10 & $19.10 \pm 1.04$ & 10 \\
9th-week & $25.00 \pm 0.51$ & 10 & $23.30 \pm 0.65$ & 10 & $22.75 \pm 0.52$ & 10 & $20.45 \pm 0.50^{* *}$ & 10 \\
10th-week & $26.60 \pm 0.91$ & 10 & $24.60 \pm 1.01$ & 10 & $23.80 \pm 1.32$ & 10 & $22.20 \pm 0.76^{* *}$ & 10 \\
\hline & & & & & & & & \\
\hline
\end{tabular}

* Significantly different from corresponding control $(\mathrm{p}<.05)$

** Highly significantly different from corresponding control $(\mathrm{p}<.01)$

$\mathrm{N}$ Number of animals. 


\section{Weight of Organs}

Table 4 represents the weight of the organs of oneand two-months-old offspring from mothers treated with nicotine during the first trimester, calculated as the percentage of body weight.

The prenatal effect of nicotine on the mean weights of organs during this stage of pregnancy was unconsistent on the weight of adrenal glands, brain, heart, liver and kidneys when compared with those of the controls.

\section{SECOND TRIMESTER}

\section{Body Weight}

The results of body weight of the offspring of mothers treated with nicotine during the second trimester are shown in Table 2 and Fig. 2.

Compared with the controls, all three experimental offspring showed highly significant $(\mathrm{p}<.01)$ reduction in the birth weight (Table 2 and Fig. 2).

The significant reduction in the body weights of the offspring prenatally treated with the small and intermediate doses continued for six weeks thereafter, while those prenatally treated with the large dose showed highly significant $(\mathrm{p}<.01)$ reduction during the testing period (Table 2). These results confirm the previous results of the first trimester which indicate also that reduction in body weight was more with the large dose than with the small dose (Fig. 1).

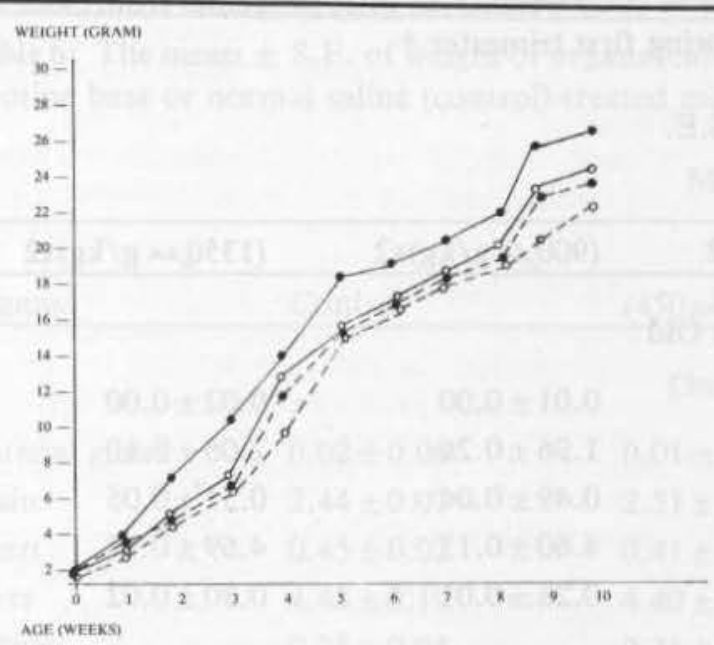

Fig. 2 Mean of weights for mice progenies from twice daily nicotine base $[(450 \mu \mathrm{g} / \mathrm{kg}) \times 2 \mathrm{O}-(900 \mu \mathrm{g} / \mathrm{kg}) \times 2--0$ or $(1350 \mu \mathrm{g} / \mathrm{kg}) \times 2$ I t treated mothers during second trimester against age in weeks.

\section{Weight of Organs}

Table 5 presents the weight of the organs of oneand two-month-old offspring from mothers treated with nicotine during the second trimester, calculated as the percentage of body weight.

The prenatal effect of nicotine on the mean weights of the organs during this stage of pregnancy caused no significant reduction except in the brain $(\mathrm{p}<.05$, $\mathrm{p}<.01$ ) with the intermediate and large doses only.
These findings are an indication that nicotine influences the brain which has just started to be formed during this stage of pregnancy. The significant reduction in brain weight when compared with the controls is an indication of the prenatal effect of the drug on the maturation and development of the brain and a confirmation of the prenatal effect of the drug administered during this stage of pregnancy on the postnatal behavior of the of fspring. ${ }^{\prime}$

\section{THIRD TRIMESTER}

\section{Body Weights}

The results of the body weights of the offspring from mothers treated with nicotine during the third trimester are shown in Table 3 and Fig. 3.

Compared with the controls, there was highly significant $(p<.01)$ reduction in the birth weight of all prenatally nicotine-treated offspring. The reduction continued throughout the whole testing period, except for those prenatally treated with the small dose which returned to normal weight when they were two months old (Table 3 ). These results confirm the previous results of the first and second trimester (Table 1 and 2, Fig. 1 and 2), but the reduction in body weight was more obvious during the third than the second and first trimesters.

\section{Weight of Organs}

Table 6 presents the weight of the organs of oneand two-month-old offspring from mothers treated with nicotine during the third trimester, calculated as the percentage of body weight.

The large dose of nicotine significantly $(\mathrm{p}<.01)$ reduced the mean of the brain weights ( $\%$ of body weight) of all prenatally nicotine-treated offspring in

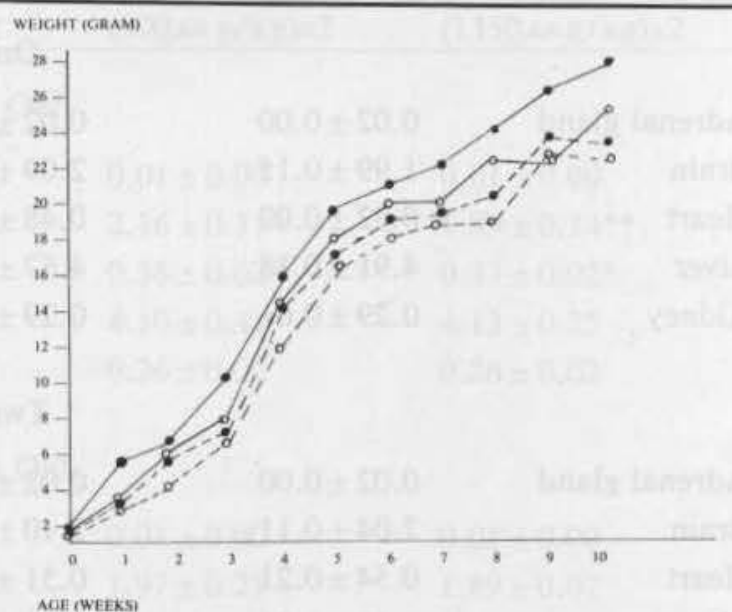

Fig. 3 Mean of weights for mice progenies from twice daily nicotine base $[(450 \mu \mathrm{g} / \mathrm{kg}) \times 2 \mathrm{O}-\mathrm{O},(900 \mu \mathrm{g} / \mathrm{kg}) \times 2$ - -0 or $(1350 \mu \mathrm{g} / \mathrm{kg}) \times 2$ 0 or control treated mothers during third trimester against age in weeks.

comparison with the controls when they were one month old. These results indicate that reduction in the brain weight disappeared when the offspring were two months old, i.e., the maturation and development of the brain of the offspring prenatally treated 
Table 3: The mean \pm S.E. of weights for mice progenies from twice daily nicotine base-or normal saline (control)-treated mothers during third trimester.

\section{Mean \pm S.E.}

\begin{tabular}{rrrrrrrrr}
\hline Age & Control & $\mathrm{N}$ & $(450 \mu \mathrm{g} / \mathrm{kg}) \times 2$ & $\mathrm{~N}$ & $(900 \mu \mathrm{g} / \mathrm{kg}) \times 2$ & $\mathrm{~N}$ & $(1350 \mu \mathrm{g} / \mathrm{kg}) \times 2$ & $\mathrm{~N}$ \\
\hline Birth-day & $1.61 \pm 0.01$ & 120 & $1.30 \pm 0.01^{* *}$ & 96 & $1.22 \pm 0.02^{* *}$ & 109 & $1.21 \pm 0.01^{* *}$ & 90 \\
1st-week & $5.70 \pm 0.12$ & 45 & $3.59 \pm 0.10^{* *}$ & 50 & $3.50 \pm 0.10^{* *}$ & 50 & $3.20 \pm 0.10^{* *}$ & 50 \\
2nd-week & $6.90 \pm 0.10$ & 45 & $6.32 \pm 0.20^{* *}$ & 50 & $5.92 \pm 0.24^{* *}$ & 50 & $4.52 \pm 0.20^{* *}$ & 50 \\
3rd-week & $10.68 \pm 0.50$ & 45 & $8.30 \pm 0.20^{* *}$ & 50 & $7.73 \pm 0.14^{* *}$ & 50 & $6.97 \pm 0.24^{* *}$ & 50 \\
4th-week & $16.01 \pm 0.31$ & 45 & $14.62 \pm 0.33^{* *}$ & 50 & $14.53 \pm 0.30^{* *}$ & 48 & $12.33 \pm 0.33^{* *}$ & 46 \\
5th-week & $19.11 \pm 0.30$ & 45 & $18.02 \pm 0.44^{* *}$ & 50 & $17.13 \pm 0.40^{* *}$ & 48 & $16.74 \pm 0.36^{* *}$ & 46 \\
6th-week & $21.03 \pm 0.75$ & 30 & $19.91 \pm 0.41$ & 30 & $19.20 \pm 0.46^{*}$ & 30 & $17.90 \pm 0.42^{* *}$ & 30 \\
7th-week & $22.03 \pm 0.80$ & 20 & $20.15 \pm 0.65$ & 20 & $19.76 \pm 0.51^{*}$ & 20 & $18.95 \pm 0.61^{* *}$ & 20 \\
8th-week & $24.45 \pm 0.76$ & 20 & $22.10 \pm 0.67^{*}$ & 20 & $20.55 \pm 0.60^{* *}$ & 20 & $19.15 \pm 0.75^{* *}$ & 20 \\
9th-week & $26.10 \pm 0.49$ & 20 & $22.60 \pm 0.52^{* *}$ & 20 & $23.97 \pm 0.60^{* *}$ & 20 & $22.75 \pm 0.42^{* *}$ & 20 \\
10th-week & $27.60 \pm 1.05$ & 10 & $24.80 \pm 1.40$ & 10 & $23.50 \pm 1.01^{*}$ & 10 & $22.50 \pm 1.45^{*}$ & 10 \\
& & & & & & & &
\end{tabular}

* Significantly different from corresponding control $(\mathrm{p}<.05)$

** Highly significantly different from corresponding control $(\mathrm{p}<.01)$

$\mathrm{N}$ Number of animals.

Table 4: The mean \pm S.E. of weight of organs (calculated as $\%$ body weight) for mice progenies from twice daily nicotine base or normal saline (control)-treated mothers during first trimester. $\dagger$

$$
\text { Mean } \pm \text { S.E. }
$$

Organs

Control

$(450 \mu \mathrm{g} / \mathrm{kg}) \times 2$

$(900 \mu \mathrm{g} / \mathrm{kg}) \times 2$

$(1350 \mu \mathrm{g} / \mathrm{kg}) \times 2$

One Month Old

$\begin{array}{lllll}\text { Adrenal gland } & 0.02 \pm 0.00 & 0.02 \pm 0.00 & 0.01 \pm 0.00 & 0.02 \pm 0.00 \\ \text { Brain } & 1.99 \pm 0.15 & 2.09 \pm 0.19 & 1.96 \pm 0.26 & 2.06 \pm 0.10 \\ \text { Heart } & 0.52 \pm 0.02 & 0.48 \pm 0.02 & 0.49 \pm 0.04 & 0.51 \pm 0.05 \\ \text { Liver } & 4.91 \pm 0.18 & 4.67 \pm 0.08 & 4.60 \pm 0.13 & 4.69 \pm 0.14 \\ \text { Kidney } & 0.29 \pm 0.01 & 0.29 \pm 0.01 & 0.28 \pm 0.01 & 0.30 \pm 0.02\end{array}$

Two Months Old

$\begin{array}{lllll}\text { Adrenal gland } & 0.02 \pm 0.00 & 0.02 \pm 0.00 & 0.01 \pm 0.00 & 0.01 \pm 0.00 \\ \text { Brain } & 2.04 \pm 0.11 & 2.10 \pm 0.11 & 2.13 \pm 0.13 & 2.07 \pm 0.13 \\ \text { Heart } & 0.54 \pm 0.21 & 0.51 \pm 0.02 & 0.52 \pm 0.04 & 0.51 \pm 0.03 \\ \text { Liver } & 5.13 \pm 0.21 & 4.89 \pm 0.07 & 4.76 \pm 0.21 & 4.70 \pm 0.09 \\ \text { Kidney } & 0.66 \pm 0.04 & 0.67 \pm 0.42 & 0.67 \pm 0.05 & 0.62 \pm 0.03\end{array}$

+10 animals per group 
Table 5: The mean \pm S.E. of weight of organs (calculated as $\%$ body weight) for mice progenies from twice daily nicotine base or normal saline (control)-treated mothers during second trimester. $\dagger$

Mean \pm S.E.

\begin{tabular}{lllll}
\hline Organs & Control & $(450 \mu \mathrm{g} / \mathrm{kg}) \times 2$ & $(900 \mu \mathrm{g} / \mathrm{kg}) \times 2$ & $(1350 \mu \mathrm{g} / \mathrm{kg}) \times 2$ \\
\hline \multicolumn{4}{c}{ One Month Old } \\
Adrenal gland & $0.02 \pm 0.00$ & $0.01 \pm 0.00$ & $0.01 \pm 0.01$ & $0.01 \pm 0.00$ \\
Brain & $2.10 \pm 0.14$ & $2.00 \pm 0.22$ & $1.79 \pm 0.08^{*}$ & $1.49 \pm 0.05^{* *}$ \\
Heart & $0.50 \pm 0.04$ & $0.48 \pm 0.01$ & $0.45 \pm 0.02$ & $0.31 \pm 0.05$ \\
Liver & $5.56 \pm 0.40$ & $5.00 \pm 0.23$ & $4.89 \pm 0.21$ & $4.00 \pm 0.14$ \\
Kidney & $0.28 \pm 0.01$ & $0.26 \pm 0.01$ & $0.24 \pm 0.01$ & $0.25 \pm 0.02$
\end{tabular}

Two Months Old

$\begin{array}{lllll}\text { Adrenal gland } & 0.01 \pm 0.00 & 0.01 \pm 0.00 & 0.01 \pm 0.01 & 0.01 \pm 0.00 \\ \text { Brain } & 2.34 \pm 0.34 & 2.12 \pm 0.12 & 2.34 \pm 0.12 & 2.00 \pm 0.15 \\ \text { Heart } & 0.64 \pm 0.03 & 0.57 \pm 0.04 & 0.47 \pm 0.01 & 0.43 \pm 0.01 \\ \text { Liver } & 5.34 \pm 0.75 & 4.71 \pm 0.17 & 4.90 \pm 0.55 & 4.69 \pm 0.09 \\ \text { Kidney } & 0.58 \pm 0.06 & 0.59 \pm 0.02 & 0.57 \pm 0.01 & 0.56 \pm 0.02\end{array}$

$\dagger 10$ animals per group

* Significantly different from corresponding control $\left(\begin{array}{ll}\mathrm{p} & .05\end{array}\right)$

** Highly significantly different from corresponding control $(\mathrm{p} \quad .01)$

Table 6: The mean \pm S.E. of weight of organs (calculated as $\%$ body weight) for mice progenies from twice daily nicotine base or normal saline (control)-treated mothers during third trimester. $\dagger$

Mean \pm S.E.

\begin{tabular}{lllll}
\hline Organs & Control & $(450 \mu \mathrm{g} / \mathrm{kg}) \times 2$ & $(900 \mu \mathrm{g} / \mathrm{kg}) \times 2$ & $(1350 \mu \mathrm{g} / \mathrm{kg}) \times 2$ \\
\hline \multicolumn{5}{c}{ One Month Old } \\
Adrenal gland & $0.02 \pm 0.00$ & $0.01 \pm 0.00$ & $0.01 \pm 0.00$ & $0.01 \pm 0.00$ \\
Brain & $2.44 \pm 0.07$ & $2.51 \pm 0.19$ & $2.16 \pm 0.11^{*}$ & $1.89 \pm 0.14^{* *}$ \\
Heart & $0.45 \pm 0.02$ & $0.41 \pm 0.04$ & $0.38 \pm 0.02^{*}$ & $0.37 \pm 0.02^{*}$ \\
Liver & $4.48 \pm 0.19$ & $4.40 \pm 0.29$ & $4.10 \pm 0.41$ & $4.13 \pm 0.25$ \\
Kidney & $0.28 \pm 0.04$ & $0.26 \pm 0.01$ & $0.26 \pm 0.02$ & $0.26 \pm 0.02$
\end{tabular}

Two Months Old

$\begin{array}{lllll}\text { Adrenal gland } & 0.01 \pm 0.01 & 0.01 \pm 0.00 & 0.01 \pm 0.00 & 0.01 \pm 0.00 \\ \text { Brain } & 2.01 \pm 0.09 & 1.10 \pm 0.12 & 1.97 \pm 0.21 & 1.89 \pm 0.07 \\ \text { Heart } & 0.48 \pm 0.03 & 0.42 \pm 0.01 & 0.43 \pm 0.01 & 0.40 \pm 0.02 \\ \text { Liver } & 5.21 \pm 0.52 & 4.49 \pm 0.39 & 3.99 \pm 0.45 & 3.89 \pm 0.20^{*} \\ \text { Kidney } & 0.57 \pm 0.15 & 0.57 \pm 0.21 & 0.54 \pm 0.07 & 0.52 \pm 0.09\end{array}$

* Significantly different from corresponding control ( $\mathrm{p} \quad .05)$

** Highly significantly different from corresponding control ( $p$ 
with nicotine during the third trimester might become more advanced as compared with the controls when they were two months old. The prenatal effect of nicotine administered during this stage of pregnancy on the postnatal development of the brain coincides with that on the postnatal behavior of the offspring. ${ }^{1}$ There was significant reduction in the mean of the heart weights ( $\%$ of body weight) of the offspring prenatally treated with the intermediate and large doses when they were one month old.

Compared with the controls, the offspring prenatally treated with the large dose showed significant $(\mathrm{p}<.05)$ reduction in the mean of liver weights $(\%$ of body weight) when they were two months old.

\section{Discussion}

There are many probable causes of postnatal growth retardation caused by prenatal nicotine (Tables 1, 2 and 3 and Fig. 1, 2 and 3). The vasoconstrictive effect of nicotine on uterine blood flow might lead to hypoxia in the fetus besides the inadequate maternal nutritional supply through the placenta ${ }^{4}$ to the developing fetus. It has also been mentioned that prenatal smoking may affect fetal growth either by diminution of the placental circulation or placental separation. ${ }^{4}$ In addition, acetylcholine is probably involved in the transport of charged molecules across the trophoblast. The release of acetylcholine and the subsequent stimulation of a placental cholinergic receptor by free acetylcholine are possibly coupled to the transport processes. This whole process was referred to as acetylcholine-stimulation-transport couples. 5 If this hypothesis is true, the placental system plays a significant role in the regulation and maintenance of fetal growth and development. Pesticides of the organophosphorus series or those containing nicotine could significantly alter the function of the placental cholinergic system by influencing the levels of acetylcholine in the placental tissue, by releasing the bound acetylcholine or by acting competitively at the proposed nicotinic cholinergic receptor. The final result of these alterations would be disturbed fetal growth and development and the consequent production of poor quality life. ${ }^{5}$ Besides, all these mentioned factors which may influence the prenatal and postnatal growth and development of the offspring from nicotine-treated mothers, inhibiting the possible lack of adipose tissue deposit which was indicated by skinniness, angularity of the body and wrinkled skin in a large number of the offspring from mothers treated with the intermediate or large doses of nicotine during the first, second and third trimesters might be one of the factors which caused fetal growth retardation and thereafter showed significant decrease of body weight at birth. ${ }^{3}$ In addition, it has been postulated that the reduction in oesterial secretion in smoking pregnant females may be the major cause for intrauterine fetal growth retardation, decrease in body weight at birth, perinatal mortality, and morbidity. ${ }^{2}$

The significant retardation in the mean weights of the brain and the heart of one-month-old offspring prenatally treated with the intermediate or large doses of nicotine during the second or third trimesters which is shown in Table 5 and 6 is probably due to the reduction in the number of the cells of the brain and the heart but not to the reduction in the cell size caused by prenatal nicotine. ${ }^{6}$ Since there is not any reduction in the brain weight of two-month-old offspring from mothers treated with nicotine during both trimesters (Table 5 and 6), it might be suggested that the prenatal effect of nicotine on the functions of the brain started to disappear after the second postnatal month. Hence, the results of the brain weights of the offspring from mothers treated with nicotine during the second and third trimesters coincide with the previously reported behavioral effects. ${ }^{\prime}$ The significant reductions in the mean weights of the liver in the twomonth-old offspring from mothers treated with the large dose of nicotine during the third trimester (Table 6) as compared with the controls might be due to the retardation of cell number but not to cell size ${ }^{6}$ and/or to decrease in the lipid content of the liver. ${ }^{9}$

\section{References}

1. Al-Hachim GM, Mahmood FA: Prenatal effect of nicotine on the ability of learning and memory. Eighth Saudi Medical Conference, King Khalid Military Academy, Riyadh, Saudi Arabia, 30 Oct,-3 Nov., 1983.

2. Beischer NA, Brown JB: Obstetrical and gynecology survey, 27:303. In: The Journal of Obstetrics and Gynaecology of the British Commonwealth, 80:815, 1972, 1973.

3. Essenberg JM, Schwind, V, et al: The effects of nicotine and cigarette smoke on pregnant female albino rats and their offsprings, the Journal of Laboratory and Clinical Medicine, 25:708, 1940 .

4. Fabro S, Sieber SM: Caffeine and nicotine penetrate the preimplantation blastocyst. Nature, London, 223:410, 1969.

5. Harbison, RD, Olubadewo J, et al: Proposed role of the placental cholinergic system in the regulation of fetal growth and development, p. 107. In: Basic and therapeutic Aspects of perinatal pharmacology edited by Morseli, P.L., Garahini, S. and Sereni, F. Raven Press, NY. p. 107, 1975.

6. Haworth JC, Ford JD: Comparison of the effects of maternal under nutrition and exposure to cigarette smoke on the cellular growth of the fetus. Amer. Journal of Obstetrics and Gynecology, 112:653, 1977.

7. Johston LM: Tobacco smoking and nicotine. Lancet, 2:742, 1942.

8. Lewis DG: Statistical methods in education, sampling theory: Means, properties and standard deviations, 110-116, 1975.

9. Mosier HD, Armstrong MK: Effects of maternal intake of nicotine on fetal and newborn rats. Proceedings of the society for experimental biology and medicine (NY), 116:956, 1964.

10. Underwood PI, Hester LL, et al: The relationship of smoking to the outcome of pregnancy. American Journal of Obstetrics and Gynecology, 91:270, 1965. 